\title{
O LUNG'IE NA EDUCAÇÃO ESCOLAR DE SÃO TOMÉ E PRÍNCIPE
}

\section{LUNG'IE IN THE EDUCATIONAL SYSTEM OF SÃO TOMÉ E PRÍNCIPE}

\author{
Ana Lívia dos Santos Agostinho* \\ Manuele Bandeira de Andrade Lima** \\ Gabriel Antunes de Araujo***
}

\begin{abstract}
RESUMO
O objetivo principal deste trabalho é tratar de questões referentes ao ensino do lung'le e identidade linguística nas escolas do Príncipe, em São Tomé e Príncipe. Para tanto, foram distribuídos questionários e feitas entrevistas com os professores de lung'le e alunos do ensino básico e secundário. A partir desse material, discutiremos questões relacionadas ao ensino de lung'le na escola, implementação da ortografia e questões sobre identidade linguística dos professores e alunos.

Palavras-chave: lung’le, línguas crioulas, São Tomé e Príncipe, planejamento linguístico, política linguística.
\end{abstract}

\section{ABSTRACT}

This paper's main objective is to cover teaching of Lung'le and linguistic identity in schools of Principe, in São Tomé and Príncipe. In order to do so, we have applied questionnaires to teachers and students of Lung'le from primary and secondary schools and interviewed them. Thus, we gathered material for discussing topics such as teaching of Lung'le in schools, orthography implementation and linguistic identity of both teachers and students. Keywords: Lung'le, creole languages, São Tomé and Príncipe, language planning, language policy.

\section{INTRODUÇÃO}

O lung'le, também conhecido como principense ou Crioulo da Ilba do Príncipe, é uma língua crioula de base portuguesa, falada na Ilha do Príncipe, na República Democrática de São Tomé e Príncipe (doravante STP), um país multilíngue da região do Golfo da Guiné. Neste trabalho apresentaremos algumas questões relacionadas ao planejamento e à política linguística do lung’le. Nossa discussão

\footnotetext{
* Universidade Federal de Santa Catarina, Florianópolis (SC), Brasil. a.agostinho@ufsc.br

** Universidade de São Paulo, São Paulo (SP), Brasil. manuelebandeira@usp.br

*** Universidade de São Paulo, São Paulo (SP), Brasil. g.antunes@usp.br
} 
estará centralizada em uma pesquisa conduzida na Ilha do Príncipe em junho de 2014, cujo objetivo era avaliar a percepção e a opinião dos alunos, professores de lung'le e pais dos alunos ${ }^{1}$ sobre a língua, seu ensino e sua relação com a escola.

Em STP, são faladas atualmente quatro línguas crioulas de base portuguesa, três autóctones (santome, lung'le e angolar) e o kabuverdianu², nativo da Alta Guiné, além do português, que é língua oficial desde 1975. O santome, o lung’le e o angolar têm estatuto de línguas nacionais de STP. Ademais, ainda são faladas outras línguas como francês e inglês, sobretudo por imigrantes de regiões anglófonas e francófonas da África, sendo ambas ensinadas nas escolas.

Como língua oficial, o português é usado em todos os atos do Estado, na educação e na mídia. Segundo Araújo \& Agostinho (2010), a norma portuguesa europeia é ensinada nas escolas e dominá-la é o objetivo do sistema escolar. Ainda de acordo com os autores, o uso generalizado do português na mídia, na escolarização, nos atos do governo, bem como o uso das variantes reestruturadas que convivem com variantes próximas da 'norma' europeia não podem ser descartados do contexto sociolinguístico de STP.

O estatuto político administrativo da Ilha do Príncipe foi aprovado pela Assembleia Nacional em 1994. A partir de então, a Ilha do Príncipe passou a ser uma Região Autônoma de São Tomé e Príncipe. Sendo assim, nos últimos anos, tem havido uma associação forte entre ser principense (termo que se refere ao gentílico da Ilha mas também ao grupo étnico) e conhecer o lung'le. Dessa forma, se de um lado o Governo Regional do Príncipe apoia essa ideia, o Governo Central se mostra menos entusiasmado em promover tal divisão. Ademais, segundo Rodrigues (2012), é comum promover o uso da língua minoritária em defesa da cultura e identidade quando há perigo de extinção, como no caso do lung’le. Para Devonish (2008), haveria dois tipos de motivações por trás do planejamento linguístico. A primeira, fazer com que a língua venha a ser, ou continue sendo, usada como expressão da identidade nacional de um povo, produzindo uma 'língua nacional'. Essa 'representa' a identidade de um povo, refletindo sua herança étnica-cultural e é normalmente utilizada em manifestações literárias e culturais, sem ser necessariamente determinada pelo Estado. A segunda, fazer com que uma variedade da língua seja usada nas instituições do Estado, tornando-se assim uma 'língua oficial'. No caso da Ilha do Príncipe, a motivação inicial para a revitalização linguística é a primeira, ou seja,

1 As entrevistas com os pais não serão analisadas neste trabalho.

2 O kabuverdianu é falado por milhares de pessoas residentes, sobretudo, nas roças ou em propriedades rurais isoladas. Há, na Ilha do Príncipe, inúmeros falantes de kabuverdianu como primeira língua dos quais muitos são monolíngues. 
passar da língua lexificadora para o crioulo, já que praticamente todos os nativos falam português. Nesse sentido, uma das questões que surgem no processo de padronização das línguas crioulas, em geral, é a dificuldade de passar do crioulo para a língua lexificadora com competência em ambas (APPEL \& VERHOEVEN 1995). Tomando o exemplo do papiamentu (falado nas ilhas de Aruba, Bonaire e Curaçao), um caso bem sucedido de padronização de uma língua crioula, Severing \& Weijer (2010) consideram que o canal mais eficiente na área de planejamento linguístico é a escola e o sistema de ensino. De acordo com Freitas (em preparação), o uso crescente do papiamentu dentro das escolas (sendo língua de instrução no nível primário e uma disciplina obrigatória no nível secundário, além de ser usado para os testes dos níveis técnico e de treinamento vocacional) foi acompanhado por uma série de conquistas em outras áreas, que permitiram a valorização dessa língua. Em 2007, o papiamentu foi alçado ao status de língua oficial das Antilhas Holandesas, junto ao holandês e ao inglês. Um ano depois, uma lei estabeleceu a grafia oficial do papiamentu (SEVERING \& WEIJER 2010). Freitas (em preparação) também menciona a existência de um curso de licenciatura na Universidade de Curaçao cujo objetivo é formar professores de papiamentu para lecionarem no ensino básico e fundamental.

Posto isso, discutiremos, neste trabalho, como a escola e o sistema de ensino têm influenciado e pode influenciar, no futuro, o planejamento linguístico da Ilha do Príncipe. Este trabalho está dividido da seguinte maneira: após esta primeira seção, na seção 2, serão discutidos alguns aspectos da situação linguística de São Tomé e Príncipe, a seção 3 tratará do lung’le na escola e na mídia ${ }^{3}$, a seção 4 discutirá a metodologia deste estudo, a seção 5 trará os resultados e discussões e a seção 6 apresentará possíveis propostas de intervenção para a melhora no sistema de ensino da referida língua, e por fim, na seção 7 , serão apresentadas nossas considerações finais.

\section{SITUAÇÃO LINGUÍSTICA DE SÃO TOMÉ E PRÍNCIPE}

A população de São Tomé e Príncipe é de aproximadamente 187 mil pessoas, segundo o Censo de 2011 (INE 2012), sendo que a Região Autônoma do Príncipe possui 7.542 habitantes. O Censo de 2011 não oferece dados sobre o bilinguismo ou o multilinguismo, porém afirma que cerca de $98,9 \%$ da população são-tomense fala o português (sem defini-lo como primeira língua, L1, ou como segunda língua,

3 As seções introdutórias (1, 2 e 3) foram baseadas em XXX (2014), com modificações. 
L2). Um total de 72,4\% falaria o santome e 2,4\%, o lung'le. Segundo Agostinho (2014), no caso do santome, os níveis de domínio da língua também variam, mas há claramente duas tendências em curso, observando-se os dados dos censos de 2001 e 2011: o santome tem se tornado a língua crioula mais falada (mesmo pelos outros grupos minoritários) e, cada vez menos, as pessoas o aprendem como língua materna, papel desempenhado pelo português que, por sua vez, tem se tornado a língua mais falada por todos os grupos étnicos. O santome é a língua nacional de STP que possui maior número de falantes e a mais prestigiada. De acordo com os resultados do Censo de 2011, 11.377 se declararam falantes do angolar, representando uma parcela de cerca de $6 \%$ da população (INE $\left.{ }^{4}, 2012\right)$. As línguas restantes (kabuverdianu, francês, inglês, entre outras), sob a rubrica 'outras línguas' no Censo, totalizam 12,8\%. Todavia, o número oficial de falantes para cada língua do arquipélago é impreciso, posto que, no Censo de 2011, era perguntado qual língua a pessoa falava e poderia haver mais de uma como resposta. Historicamente, dados confiáveis sobre o número de falantes nativos do lung'le são uma questão controversa. Essa falta de precisão quanto ao número de falantes de lung'le se deve, dentre outras razões, à própria dificuldade em encontrar habitantes no Príncipe que falem a língua, dificuldade já documentada na década de sessenta e setenta do século XX por Valkhoff (1966, p. 85). Günther (1973, p. 50) aponta que o lung'le estaria em processo de extinção, sendo substituído pelo santome e pelo português. Maurer (2009), por sua vez, afirma que, embora o Censo de 2001 aponte que aproximadamente mil pessoas da população da Ilha do Príncipe seriam falantes do lung'le, trata-se de um dado superestimado, a não ser que se considere o conhecimento passivo da língua como critério. Segundo Agostinho (2014), atualmente, há mais falantes nativos de kabuverdianu no Príncipe do que falantes nativos de lung'le, havendo, inclusive, falantes monolíngues de kabuverdianu. Além disso, ainda de acordo com Agostinho (2014), o lung'le é falado por cerca de 200 pessoas geralmente com mais de sessenta anos, com níveis de competência variados, e não há mais falantes monolíngues.

Nos últimos anos, o lung'le tem tido uso restrito e está limitado à população da Ilha do Príncipe. Ao mesmo tempo, é possível perceber um aumento de interesse em relação à cultura principense, em geral, e ao aprendizado do lung'le, em particular (AGOSTINHO 2014). Alguns jovens têm um conhecimento passivo do lung'le, mas não têm competência linguística para falar. Segundo Espírito Santo (em preparação), 57\% dos alunos do ensino secundário afirmam ter um familiar

4 Instituto Nacional de Estatística de São Tomé e Príncipe. 
falante de lung'le, mas apenas 18\% alegam compreender a língua. Observou-se também que a língua não é transmitida intergeracionalmente. Um dos motivos apontados pelos próprios habitantes da Ilha do Príncipe é a relutância que os pais apresentavam em transmitir a língua, pois pensavam que seu aprendizado atrapalharia o do português. Em relação a isso, Pinho (2008) argumenta que falantes de línguas minoritárias podem ter atitudes positivas para com a sua língua, mas podem não querer transmiti-las por razões como a suposta interferência no aprendizado da língua majoritária, preconceitos com o 'sotaque' e sentimentos de inferioridade. Outrossim, os habitantes lembram que os pais e avós falavam em lung'le, porém crianças poderiam sofrer abusos físicos e psicológicos se não respondessem em português. Segundo Agostinho (2014), mesmo entre os falantes competentes em lung'le, a língua utilizada em seu cotidiano atualmente é predominantemente o português.

Crystal (2000, p. 19) propõe uma tipologia sobre o estado de preservação das línguas dividida em três níveis: seguro, ameaçado ou extinto. Além dessa tipologia, Michael Krauss (1992, p. 4) propõe o estado moribundo para aquelas que não estão sendo mais adquiridas como língua materna pelas crianças. Para Crystal (2000, p. 20), essa categoria captura uma noção que vai além de um mero estágio de ameaça, porque tal classificação, baseada em uma analogia com as espécies de animais que são incapazes de reproduzir, aborda a característica principal de línguas dessa categoria: a inviabilidade de uma transmissão intergeracional. Em STP, fatores como a mídia e a escolarização (fenômenos pós-independência) dão ao português um prestígio que não pode ser rivalizado e colaboram para um abandono crescente das línguas nacionais (Araújo \& Agostinho 2010). Embora esse fenômeno esteja também associado ao processo de urbanização dos últimos quarenta anos. Ao mesmo tempo, os dados longitudinais dos Censos de 1981 (STP 1987), 2001 (INE 2001) e 2011 (INE 2012) mostram uma crescente difusão do português em todos os grupos étnicos e o abandono paulatino das línguas nacionais. No tocante à classificação do lung'le como língua em extinção, é preciso considerar os fatores indicativos do nível de ameaça linguística: (i) o número de crianças que adquirem a língua como primeira; (ii) as atitudes da comunidade face à língua em questão; e (iii) o grau de impacto de outras línguas 'glotocidas' (CRYSTAL 2000, p. 19-20). Portanto, o lung'le, de acordo com a tipologia de Crystal (2000, p. 1-20), pode ser categorizado como uma língua ameaçada, devido à ausência de falantes como primeira língua (que sejam crianças), somada a isso, tem-se atitude da comunidade que não tem buscado, majoritariamente, fazer uso regular do lung'le em todas as circunstâncias sociais, e, por fim, é preciso considerar o nível de impacto de outras 
línguas, como o português, língua oficial e mais utilizada em todas as esferas sociais, e o kabuverdianu, haja vista que há muitos falantes descendentes dos trabalhadores contratados que chegaram na ilha no final do século XIX e começo do XX $X^{5}$.

Além de fatores sociais, há uma razão histórica para o declínio do número de falantes do lung'le: no início do século XX, uma epidemia de doença do sono dizimou a população nativa do Príncipe, restando apenas 300 pessoas (GÜNTHER 1973). Sendo assim, devido à situação de depopulação da Ilha e à escassez de mão-de-obra, foram levados para as propriedades rurais agroindustriais, localmente conhecidas como 'roças', trabalhadores assalariados de outras regiões, principalmente de Cabo Verde.

Em resumo, STP é um país multilíngue e suas línguas nacionais, bem como as outras línguas faladas no arquipélago constituem, ao lado do português, a complexa ecologia linguística local. Ao mesmo tempo, o lung'le é a língua minoritária com menos falantes e mais ameaçada tanto pelo português como pelo kabuverdianu.

\section{0 LUNG'IE NA EDUCAÇÃO E NA MÍDIA}

Appel e Verhoeven (1995) defendem que a política linguística se manifesta em dois principais domínios: na educação e na mídia. Sendo assim, trataremos de ambos nesta seção.

Desde 2009, o lung'le vem sendo ensinado nas escolas, devido, sobretudo, ao incentivo do Governo Regional do Príncipe à difusão da cultura principense. A tarefa de ensinar a língua foi entregue aos principenses que ainda têm conhecimento da língua embora, não sejam especificamente treinados para lecionar a língua, nem façam uso de algum material didático. No que diz respeito ao perfil dos docentes, há nove professores, de 24 a 64 anos, sendo um deles não alfabetizado. Os professores lecionam cerca de 14 horas/aula por mês e recebem cerca de 20 euros por mês (apenas nos meses letivos) sem auxílio alimentação e transporte ${ }^{6}$. A cada quinzena, os professores se reúnem para programar as aulas, porém a discussão é muitas vezes pautada na ortografia, já que o lung'le ainda não tinha uma ortografia padrão até 2010 e - ainda em 2016, os professores não se inteiraram

\footnotetext{
5 Nesse sentido, no cenário multilíngue de STP, ao mesmo tempo em que o português é uma ameaça a todas as línguas, o santome também atua como língua glotocida em relação ao angolar, ao lung’le e ao kaboverdianu, pois é a língua local mais prestigiada.

6 Dados de 2014.
} 
do alfabeto unificado ${ }^{7}$ - a discussão sobre a escolha entre uma escrita fonética ou etimológica ainda não havia sido resolvida. De fato, como sugerido por Auroux (1992), "a ortografia se torna um problema, às vezes incessantemente discutido". Apesar dos encontros quinzenais, cada professor define sozinho de que forma e com quais materiais ministrará suas aulas, pois trabalham sem material didático padronizado e oficial. Para auxiliá-los nessa tarefa, instrumentos linguísticos estão sendo preparados desde 2009 por pesquisadores, utilizando-se o ALUSTP. Serão publicados um método pedagógico por Agostinho (2014) e um dicionário lung’leportuguês, português-lung'le (ARAÚJO et al., em preparação).

Entre 2009 e 2015, foi oferecida nas escolas uma disciplina de lung'le optativa e sem avaliações, desde a pré-escola (crianças de 3 a 5 anos) até a $11^{\text {a }}$ classe $^{8}$. A partir de 2016, as aulas a partir da $5^{\text {a }}$ classe passam a ser obrigatórias, vindo a ser avaliada com nota e presença, além de atividades em sala de aula.

No que diz respeito à mídia, a televisão local tem três canais abertos, sendo um são-tomense (Televisão São-Tomense (TVS), que não tem programação 24h) e dois portugueses (Rádio e Televisão Portuguesa (RTP) e RTP África), todos transmitidos em português (AGOSTINHO 2014). O canal são-tomense exibe alguns programas em santome, mas não em lung'le. O canal também exibe videoclipes nacionais com músicas em santome e algumas em lung'le. Há um programa de rádio em lung’le, transmitido semanalmente na Rádio Regional do Príncipe. As emissões radiofônicas consistem em conversas informais sobre a língua, sobre a vida na Ilha do Príncipe, sobre política, apresentações musicais, lições sobre a língua, traduções para o lung'le, entre outros. Agostinho (2014) afirma que os ouvintes podem telefonar para a produção do programa radiofônico e tirar dúvidas sobre a língua durante as transmissões. No entanto, os programas não são reprisados por não haver recursos tecnológicos para a gravação das emissões.

Além das aulas na escola e programas de rádio, há um encontro semanal chamado Palixa na lung'Ie 'Conversar em lung'Ie', realizado no Centro Cultural do Príncipe, em que se elege um tema sobre o qual os presentes deverão discorrer em

7 A fim de preencher a lacuna em relação a um sistema de grafia para as suas línguas nacionais, o Governo de STP patrocinou a criação do Alfabeto Unificado para as línguas de São Tomé e Príncipe (ALUSTP), elaborado por uma comissão formada por acadêmicos e intelectuais (cf. xxx 2010). Tal proposta foi sancionada pelo Governo de São Tomé e Príncipe em 2013. Com a implementação do ALUSTP em período experimental até 2018, todos os instrumentos linguísticos deverão passar a utilizar a grafia padronizada (xxx 2014). No entanto, apesar de sua implementação, a proposta ortográfica continua desconhecida pela maioria dos principenses, inclusive pelos professores de lung'le.

8 Equivalente ao 2o ano do Ensino Médio no Brasil. 
lung'le. $\mathrm{O}$ encontro também é, muitas vezes, transmitido pela Rádio Regional do Príncipe. Agostinho (2014), ao participar desses encontros, bem como do programa semanal de rádio, afirma que há cada vez mais jovens interessados em aprender a língua, apesar de a maioria dos participantes do Palixa na lung'le ser formada por pessoas com mais de 60 anos. O programa de rádio é muito popular entre todas as faixas etárias.

O planejamento e a padronização da língua, por meio de instrumentos linguísticos, preencherá uma lacuna no ensino do lung’le, abrindo caminho para novas publicações e materiais didáticos, bem como colaborará com o crescente interesse pela língua e para a sua promoção nas escolas e na mídia como língua nacional de São Tome e Príncipe.

\section{METODOLOGIA}

Em 2014, foi realizada uma série de entrevistas com os professores de lung'le e, ao mesmo tempo, distribuídos questionários aos alunos de $7^{\mathrm{a}}$ à $11^{\mathrm{a}}$ classe $^{9}$, aos pais desses alunos e também aos professores de lung'le. Os docentes entrevistados lecionam nas escolas: Jardim Minu-kêtê (pré-escolar), Abade (pré-escolar e básica), Nova Estrela (pré-escolar e básica), Hospital Velho (pré-escolar e básica), Rua Feliz (pré-escolar e básica), Aeroporto (básica), Sundy (básica), Paula Lavres (básica), Santo António II (básica e secundária) e Padrão (secundária). Foram entrevistados e entregues questionários a oito dos nove professores de lung'le. As escolas visitadas para a entrega dos questionários aos alunos foram Santo António II (básica e secundária) e Padrão (secundária), ambas na cidade de Santo António e a faixa etária dos alunos era de 12 a 21 anos. No tocante ao número de participantes, quarenta e cinco alunos e dezoito pais de alunos responderam aos questionários separadamente.

É preciso salientar que questionários, cuja língua veículo era o português, e sua aplicação no contexto escolar do Príncipe são passíveis de limitações, uma vez que alunos e professores de lung'le têm dificuldade de leitura e compreensão de texto em língua portuguesa. Segundo Christofoletti (2013), o aprendizado da variedade padrão de português fora da capital (cidade de São Tomé) é precário, o

\footnotetext{
9 Equivalente ao 80 ano do ensino Fundamental, até o 20 ano do Ensino Médio no Brasil. Na época em que os questionários foram distribuídos, não havia 12a classe, 30 ano do Ensino Médio brasileiro, no Príncipe, somente na Ilha de São Tomé.
} 
ensino é de baixa qualidade e a formação dos professores, quando há algum tipo de treinamento profissional, é limitada ${ }^{10}$, o que dificulta uma pesquisa baseada em leitura e escrita. Por este motivo, elaboramos questionários simplificados, que podem ser observados em anexo.

Os informantes, muitas vezes, respondem o que acreditam ser a resposta "ideal" (cf. VAUX et al. 2007), mesmo que isso gere um viés para a interpretação do material pelos pesquisadores. Por este motivo, optamos por elaborar um questionário que, além de perguntas com opções, contivesse espaço para que os informantes escrevessem as razões de suas respostas em todas as perguntas cujas respostas eram sim-não. Além disso, foi enfatizado que o questionário não seria utilizado para qualquer outro fim que não fosse a pesquisa e que todos poderiam responder o que pensavam sobre as aulas, a educação, o Governo etc. Mesmo assim, é difícil garantir que as respostas não sejam enviesadas, uma vez que os informantes poderiam se sentir obrigados a escrever de maneira positiva sobre os temas tratados. Em todos os casos, a identidade linguística é vista como 'eufórica', nos termos de Fiorin (1993), apesar de poder ser apenas uma reprodução do discurso vigente em alguns casos, uma vez que o discurso é social e aprendido, modelando a visão de mundo do falante (Fiorin 1993).

Por haver oito (dos nove) professores de lung'le disponíveis, as entrevistas foram organizadas na ocasião do preenchimento do questionário. Como não era viável entrevistar todos os alunos durante a coleta dos questionários, enfatizamos a importância de respostas dissertativas em todas as questões. Na seção 5, trataremos das respostas nas entrevistas/questionários realizados pelos professores e alunos.

\section{DISCUSSÃO}

Nesta seção observaremos, a partir das respostas dos questionários e das entrevistas, as atitudes em relação ao lung'le e comentários sobre questões referentes ao ensino e à identidade principense.

10 Segundo o autor, apesar de a variedade do português europeu padrão ser utilizada nos materiais didáticos e ser ensinada nas escolas, os professores são-tomenses não a dominam (Christofoletti 2013). Ao mesmo tempo, alguns professores portugueses acabam por estigmatizar as línguas nacionais através da difusão de conceitos não científicos, tratando as línguas crioulas como um tipo de português errado ou um dialeto do português, contribuindo para a propagação de preconceitos linguísticos. 


\subsection{PROFESSORES}

Oito professores responderam aos questionários e foram entrevistados. As entrevistas serviram para desenvolver mais profundamente alguns temas e também para esclarecer algumas questões levantadas nos questionários. Como era de se esperar, todos os professores entrevistados concordam que o lung'le deveria ser ensinado nas escolas e que deveria ser disciplina obrigatória (Tabelas 1 e 2).

Tabela 1: Você acha que o lung'le deveria ser ensinado na escola?

\begin{tabular}{ll}
\hline Sim & $100 \%$ \\
Não & $0 \%$ \\
\hline total & $100 \%$ \\
\hline
\end{tabular}

Tabela 2: Você acha que o lung'le deveria ser matéria obrigatória?

\begin{tabular}{ll}
\hline Sim & $100 \%$ \\
Não & $0 \%$ \\
\hline total & $100 \%$ \\
\hline
\end{tabular}

Segundo um professor, o lung'le é "uma matéria como outra qualquer" e, outro defende que deveria mesmo ser disciplina obrigatória, pois "assim os alunos dariam mais atenção [à língua] porque a maioria dos jovens não liga". Ao mesmo tempo, todos os docentes também afirmaram gostar de dar aulas de lung'le e acham importante que os jovens aprendam a língua (Tabelas 3 e 4). Quando indagados, alguns alegam gostar de ensinar por terem o poder de ajudar na preservação da língua e de servirem como instrumento para que mais pessoas a conheçam.

Tabela 3: Você gosta de dar aulas de lung'le?

\begin{tabular}{ll}
\hline Sim & $100 \%$ \\
Não & $0 \%$ \\
\hline total & $100 \%$ \\
\hline
\end{tabular}

Tabela 4: Você acha importante os jovens aprenderem lung'le?

\begin{tabular}{ll}
\hline Sim & $100 \%$ \\
Não & $0 \%$ \\
\hline total & $100 \%$ \\
\hline
\end{tabular}




\subsubsection{Dificuldades}

Nas entrevistas, perguntamos aos professores quais eram as maiores dificuldades que encontravam em seu trabalho. A primeira questão levantada dizia respeito à remuneração, caracterizada por salários baixos e pelo não pagamento durante as férias escolares. Outro problema alegado foi o custo do transporte, pois os professores que moram em áreas rurais e/ou dão aula nessas áreas precisam pagar por uma condução até a escola ou andarem por horas em estradas, muitas vezes não pavimentadas. Um dos professores afirma que gastaria o dobro do salário em condução para as duas comunidades afastadas em que dá aula e que, portanto, fazia os trajetos a pé. Para ilustração, uma viagem de ida e volta de uma área a outra em mototáxi, meio mais comum de transporte na Ilha, custa em torno de 1 euro. Como há professores que dão aula em mais de uma escola e, em diferentes dias da semana, o salário de 20 euros pode não contemplar sequer gastos com locomoção.

Apesar do apoio do Governo Regional do Príncipe que, desde 2009, tem tentado promover o lung'le, os professores reclamam da falta de metodologia de ensino e da assiduidade dos alunos às aulas. Para muitos, a preocupação do Governo Regional se limita a uma questão de imagem, pois os políticos preferem, por exemplo, crianças cantando em lung'le nas festas tradicionais a investir pesadamente nos meios de promover o lung'le como língua nacional. Junto a isso, segundo alguns docentes, os burocratas, responsáveis pela Educação no Príncipe, mostram-se insensíveis aos pleitos dos professores.

\subsubsection{Planejamento das aulas e ortografia}

A partir da análise das entrevistas e dos questionários, foi verificado que nenhum dos professores tem qualquer formação universitária ou formação técnica para lecionar, seja em educação em geral, pedagogia, magistério ou em ensino de língua materna ou estrangeira. Nas entrevistas, os professores mais novos contam que se reúnem com os mais velhos para o planejamento das aulas, mas que carecem de uma formação adequada. Nesse sentido, basicamente, os professores se encontram a cada duas semanas para planejar as aulas e as reuniões consistem em decidir o vocabulário que será ensinado e discutir ortografia. Um dos professores é o coordenador do grupo, responsável pela organização das reuniões e por ensinar a ortografia das palavras aos outros. A grafia utilizada por ele não é aquela segundo o padrão ALUSTP. Observemos alguns trechos ${ }^{11}$ de parte das discussões que ocorrem nos encontros:

11 A transcrição ortográfica reflete o português popular da Ilha. 
1)

a) "O planejamento das aulas é feito de 15 em 15 dias através de objetos que nos rodeiam, as plantas, os animais, as pessoas".

b) "Temos sempre que reunir e planejar a semana próxima. Hoje é: carteira [escolar] é kata, banco é ubanku, livro é livu, lanche é kumê".

c) "Consoante à planificação (...), nós traduzimos o português em lung'le".

Observamos que as aulas consistem basicamente em aprendizagem de vocabulário e tarefas de traduções de algumas sentenças do português (cf. AGOSTINHO 2014). Contudo, os professores atribuem a falta de materiais didáticos e de dicionários às limitações das atividades didáticas em sala de aula.

O ALUSTP não está ainda difundido no Príncipe e, por essa razão, o Governo Regional optou por desencorajar a escrita do lung'le na sala de aula. Sendo assim, os professores foram orientados a não escreverem em lung'le na sala de aula. Apesar disso, a escrita em sala é uma realidade, ainda que a maioria dos professores desconheça a existência do ALUSTP ou prefiram não utilizá-lo. Sendo assim, os professores utilizam a grafia do coordenador do grupo ou uma grafia própria. Ressaltamos, contudo, que não se trata de uma proposta sistemática elaborada por eles e as soluções são normalmente idiossincráticas. Tomemos o exemplo da palavra kata "carteira escolar", assim grafada seguindo as regras do ALUSTP. A maioria dos professores prefere utilizar a forma $<$ cata $>$, ou seja, empregando uma ortografia de origem etimológica inspirada na ortografia portuguesa. Há ainda soluções individuais tais como <catha $>$. Isso gera um problema, uma vez que palavras de origem portuguesa, mas que sofreram modificações, como dêsu "deus", requerem soluções ad hoc. Neste caso, é possível encontrar três formas conflitantes, duas delas inspiradas na ortografia portuguesa. Além do ALUSTP, para o fonema /s/, por exemplo, na escrita dos professores, há $<$ dêssu $>$ e $<$ dêçu $>$, ou seja, a escolha de $<$ ss $>$ ou $<$ ç $>$ não é totalmente arbitrária, mas gera um conflito. A terceira forma conflitante diz respeito a itens como $<$ catha $>$ que difere de $<$ cata $>$, conforme prevê o ALUSTP, apresentando uma grafia que pouco se aproxima da escrita tradicional portuguesa ou da referida proposta ortográfica. Observemos alguns comentários feitos pelos professores sobre as suas soluções ortográficas:

2)

a) "É assim: nós lung’le, cada um escreve da maneira que pensa que a frase deve ser escrita porque a língua é complicada tanto para falar como para escrever". 
b) "Decido escrever da maneira que entendo".

c) "No meu caso, decido como [escrevo] ou [escrevo] como foi planejado".

d) "Se tiver um folheto, é só seguir. Outra [palavra fica] por conta própria".

e) "Como eu falo, assim escrevo".

f) "A língua deve ser [escrita] como [se] pronuncia".

Podemos interpretar a observação em (2a) como a inadequação da ortografia utilizada pelos professores, vista pelos olhos dos demais, com o viés da suposta dificuldade do lung'le escrito e falado. Assim, a ideia de que o lung'le é uma língua difícil se mantém difundida mesmo entre os professores. Durante a pesquisa foi possível observar que essa concepção é comum entre os principenses sobre a sua própria língua, ao passo que o sentimento em relação santome é oposto, pois essa é considerada mais fácil de se aprender. Em (2b), (2c) e (2d), podemos observar que os professores decidem escrever de forma idiossincrática embora (2d) demonstre uma propensão a seguir um padrão comum. Contudo, em (2e) e (2f), os professores parecem acreditar que a língua escrita é uma representação da fala, hipótese que carece de evidências (Cf. CAGLIARI 1994), embora amplamente difundida entre leigos.

Todos os professores dizem concordar com uma ortografia unificada, mas muitos não concordam com o ALUSTP, mesmo sem sequer conhecê-lo. Há uma certa resistência a uma ortografia que se distancie da portuguesa e há também a alegação de que faltou representatividade do Príncipe na decisão, uma vez que não havia nenhum principense na comissão, e de que houve imposição do ALUSTP por São Tomé, o que se configura, mais uma vez, como pontas soltas no discurso local que reforçam as questões de subserviência ao modelo colonial, de etnocentrismo e de identidade (cf. 5.1.4) beligerante. Apesar de concordarem que uma ortografia unificada traria mais-valia para todos, embora haja resistência dos professores em adotar o ALUSTP, é possível observar que eles reconhecem, por outro lado, a necessidade de uma grafia unificada para tornar o ensino mais eficiente e objetivo como em (3c):

3)

a) "Sim, que tivesse a mesma escrita para compreensão de todos: os linguistas, os falantes, todos que sabem algo de lung'le".

b) "[Sim], para que tivesse uma só forma de escrever".

c) "Ficaria mais prático, principalmente para os professores e também a existência de uma gramática". 


\subsubsection{Identidade}

Guisan (2009) define identidade como "pertencer a uma tradição". Segundo o autor, uma comunidade se caracteriza por sua(s) variante(s), que é/são o que permite diferenciar um grupo do outro. A percepção do que é igual ou diferente se faz pela língua e esta é o principal símbolo identitário para se separar de outros grupos, já que é através dela que a cultura de um povo é transmitida (GUISAN 2009). Garrett (2008, p. 31) defende que, mesmo que qualquer língua seja percebida por seus falantes como inferior em relação à língua oficial, ela pode ser tratada como um símbolo de sua identidade. No caso do lung'le, há uma correlação entre ser principense e saber lung'le, apesar de a língua ser pouco falada pelos mais jovens. A reação mais comum que encontramos ao falar em lung'le com os nativos se relacionava à identidade: "eu que sou principense não falo". Dito isso, observemos alguns trechos das entrevistas/questionários:

4)

a) "Deve [ser ensinada] e muito bem porque é a nossa língua materna e nós que somos naturais devemos guardar [guardá-la]".

b) "Porque o lung'le é que identifica se a pessoa é mesmo do Príncipe".

c) "Porque é nossa identidade e está a [se] perder".

d) "Os mais velhos se vão e os jovens poderão ensinar [a língua] aos que virão".

e) "Para que seja uma língua falante [falada] em todos os níveis sem exceção de raças, como outras línguas estrangeiras".

Podemos observar nas respostas uma preocupação com a identidade relacionada ao lung'le e com sua preservação (4a-d). Nesse sentido, uma canção em lung'le, composta por Frutuoso dos Santos Luís Fernandes (Tuta), ensinada nas escolas que diz: "É para gente saber que o lung’le é nossa carteira de identidade" (Cf. AGOSTINHO 2014: 337-338) reflete uma visão de mundo principense em relação à sua língua e etnicidade. $\mathrm{O}$ uso da expressão "carteira de identidade" demonstra o desejo de se fazer notar como diferente, possivelmente em relação aos nativos da Ilha de São Tomé, uma vez que sua cultura (música, dança, culinária, etc) é diversa, principalmente em relação à cultura do grupo étnico forro, falante do santome. A colocação em (4e), por sua vez, demonstra um receio em relação às outras línguas, ou seja, ao que é diferente sendo a língua uma forma de manifestar essa diferença. 


\subsection{ALUNOS}

Nos questionários dos alunos, havia três perguntas relacionadas à frequência nas atividades de lung'le. Nessas perguntas, não havia espaço para uma resposta dissertativa e os alunos eram direcionados a responder marcando uma das opções: sempre, quase sempre, às vezes, quase nunca, nunca. Na Tabela 5, podemos observar as respostas referentes à pergunta: Você vai às aulas de lung'le?

Tabela 5: Você vai às aulas de lung'le?

\begin{tabular}{lc}
\hline Sempre & $36 \%$ \\
Às vezes & $21 \%$ \\
Nunca & $18 \%$ \\
Quase sempre & $14 \%$ \\
Quase nunca & $11 \%$ \\
\hline total & $100 \%$ \\
\hline
\end{tabular}

Dos alunos que responderam os questionários, 50\% afirmam frequentar as aulas sempre ou quase sempre, $21 \%$ dizem frequentar às vezes e $29 \%$ nunca ou quase nunca. Isso mostra que apenas metade dos alunos costuma ir às aulas, legitimando a queixa dos professores em relação à baixa assiduidade dos alunos. Na Tabela 6, podemos ver as respostas referentes à questão: Você vai ao Palixa na lung'le? .

Tabela 6: Você vai ao Palixa na lung'le?

\begin{tabular}{ll}
\hline Nunca & $74 \%$ \\
Às vezes & $14 \%$ \\
Quase sempre & $7 \%$ \\
Quase nunca & $8 \%$ \\
Sempre & $0 \%$ \\
\hline total & $100 \%$ \\
\hline
\end{tabular}

Podemos observar que a maioria, $79 \%$, respondeu que nunca ou quase nunca compareceu aos encontros, ao passo que $14 \%$ responderam frequentar às vezes $\mathrm{e}$ $7 \%$ afirmam frequentar quase sempre. Nenhum aluno respondeu frequentar sempre os encontros. De fato, poucos jovens participam dos encontros, apesar de o número de participantes em geral ter aumentado em relação aos anos anteriores, como observado durante a pesquisa. 
$\mathrm{Na}$ Tabela 7, podemos observar as respostas referentes à questão: Você ouve o programa de rádio de lung'le?

Tabela 7: Você ouve o programa de rádio de lung'le

\begin{tabular}{ll}
\hline Às vezes & $48 \%$ \\
Sempre & $28 \%$ \\
Quase sempre & $13 \%$ \\
Nunca & $11 \%$ \\
Quase nunca & $0 \%$ \\
\hline total & $100 \%$ \\
\hline
\end{tabular}

É possível observar que $48 \%$ dos alunos responderam que ouvem o programa radiofônico às vezes, enquanto $41 \%$ afirmam ouvir o programa sempre ou quase sempre. Apenas $11 \%$ afirmam não ouvir nunca. Esse resultado mostra a relativa popularidade do programa de rádio entre os jovens, como já apontado em Agostinho (2014). De uma maneira geral, a rádio é ainda muito popular na Ilha.

\subsubsection{Sala de aula}

Dos alunos que responderam ao questionário, 91\% acham importante que o lung'le seja ensinado na escola, mas $67 \%$ acreditam que não deveria ser disciplina obrigatória.

Tabela 8: 0 lung'le deveria ser ensinado na escola?

\begin{tabular}{ll}
\hline Sim & $91 \%$ \\
Não & $9 \%$ \\
\hline total & $100 \%$ \\
\hline
\end{tabular}

Tabela 9: 0 lung'le deve ser matéria obrigatória?

\begin{tabular}{ll}
\hline Não & $67 \%$ \\
Sim & $33 \%$ \\
\hline total & $100 \%$ \\
\hline
\end{tabular}

Os motivos alegados pelos alunos para que a disciplina não seja obrigatória variam do desinteresse em aprender o lung'le, associado ao fato de alguns alunos acharem que se trata de uma língua que deve ser ensinada entre gerações, sendo uma 
tarefa familiar, sobretudo dos pais e dos avós, e não da escola, e, por fim, destacam o fato de o lung'le não ser a língua materna ou de herança de muitos dos alunos que responderam ao questionário, uma vez que o número de descendentes de caboverdianos na Ilha do Príncipe, falantes do crioulo de Cabo Verde, supera amplamente o número de descendentes de principenses étnicos. Em relação à falta de interesse, que abordaremos também na próxima seção, um aluno escreve que "(...) quando [há] um peixe podre no meio de vários peixe bom, todos tão podre, e é isso que acontece porque, se alguém tem vontade de aprender, ele luta pra aprender, mas se os outros não querem, ele não aprende nada". Este trecho demonstra a insatisfação do aluno em relação ao comportamento de alguns colegas de classe à postura nas aulas e à dificuldade de querer aprender em um ambiente em que poucos têm esse interesse. Além disso, o trecho aponta que a única possibilidade de aprender seria com todos os alunos interessados, o que dificilmente ocorreria, já que um desinteressado, segundo ele, seria suficiente para afetar os demais. Além desse, há outros trechos em que o aluno coloca os 'outros' como o problema, sem reflexão sobre a conduta que eles mesmos poderiam demonstrar para uma mudança de atitude.

Do total de alunos, 70\% alegam participar das aulas. Apesar da Tabela 5 mostrar que $50 \%$ dos alunos afirmam comparecer às vezes, quase nunca ou nunca nas aulas de lung'le, a Tabela 10 mostra que, segundo eles, a participação é alta quando estão presentes na sala de aula.

Tabela 10: Você participa das aulas de lung'le?

\begin{tabular}{ll}
\hline Sim & $70 \%$ \\
Não & $30 \%$ \\
\hline total & $100 \%$ \\
\hline
\end{tabular}

\subsubsection{Preferências e perspectivas}

Quando questionados sobre as atividades favoritas na sala de aula, as respostas dadas pelos alunos foram diversas: cantar, ouvir bistórias, aprender verbos, traduzir, entre outros. Já as respostas sobre as atividades e atitudes menos agradáveis em sala de aula abordaram questões relativas especialmente a comportamento dos alunos, tais como não prestar atenção, fazer barulho, não comparecer às aulas:

5)

a) "É quando o colega não presta atenção na aula".

b) "O comportamento dos alunos na sala de aula". 
c) "Eu não gosto muito de conversas que não estão relacionadas com a aula".

d) "É quando os alunos ficam a falar e o professor manda calar e eles não ouvem o professor".

e) "Quando os alunos fazem barulho e o professor fica muito chateado e às vezes abandona a turma".

f) "A falta de alunos".

Outra questão que pode ser observada nas respostas dos alunos é a falta de metodologia e técnica dos professores em sala de aula. Alguns alunos afirmam não gostar de escrever a língua, o que é um reflexo da falta de padronização ortográfica utilizada nas aulas. Muitos professores não escrevem a língua seguindo o modelo do ALUSTP, o que dificulta o aprendizado em sala de aula (6a-b), pois cada docente escreve de forma idiossincrática. Além disso, há queixas de não entendimento por parte dos alunos, o que demonstra novamente uma falta de preparo pedagógico dos professores em relação ao nível de cada série (6c). Finalmente, alguns alunos comentam sobre problemas de interação na relação professor/aluno $(6 \mathrm{~d}, \mathrm{f})$.

6)

a) "Não gosto muito de escrever".

b) "Não gosto de falar o que eu não sei falar, nem de escrever o que eu não sei escrever".

c) "É quando eu não consigo entender o que eles falam".

d) "A maneira como professor fala com alunos quando os alunos não gosta de participar."

Quando questionados sobre o que poderia melhorar, as respostas se relacionam a questões de didática, à formação dos professores, à falta de preparação das aulas e de material didático:

7)

a) "Acho que seria fixe também se for um professor formado e com vontade pra trabalhar e explicar".

b) "Métodos de explicação dos professores".

c) "Reforçar mais o ensino".

d) "Ter mais conteúdo".

e) "Os professores e alguns métodos de educação para essa aula [poderiam melhorar]". 
f "Acho que deveria ter livros".

g) "Ter mais e melhores professores de lung'le".

h) "É dar uma aula mais objetiva (...) e aprofundada".

i) "O modo de explicar deve ser claro e compreensível".

\subsubsection{Identidade}

Em relação à identidade, pudemos observar que os temas mais recorrentes são a ligação com a terra e com a família, a exclusividade da língua e sua exposição fora do Príncipe. Todos os alunos afirmaram achar importante aprender o lung'le e 98\% dizem ter vontade de fazê-lo (ver Tabelas 11 e 12).

Tabela 11: Você acha importante aprender lung'le?

\begin{tabular}{ll}
\hline Sim & $100 \%$ \\
Não & $0 \%$ \\
\hline total & $100 \%$ \\
\hline
\end{tabular}

Tabela 12: Você quer aprender lung'le?

\begin{tabular}{ll}
\hline Sim & $98 \%$ \\
Não & $2 \%$ \\
\hline total & $100 \%$ \\
\hline
\end{tabular}

Para Orlandi (2009), a língua é parte da identidade pessoal do falante além de ser patrimônio histórico do grupo e da humanidade, uma vez que a perda de uma língua equivale à perda da cultura. É possível observar através dos excertos em 8 que estas preocupações existem na camada jovem da população do Príncipe. Observamos também que a língua é tida para os alunos como uma forma de se distanciar de São Tomé e dos outros países (8d-g) e como afirmação de uma identidade que não deve ser menosprezada, como também mostra (8h).

8)

a) "Lung'le é a língua da nossa terra".

b) "Porque é nossa língua paterna e materna".

c) "Para nos comunicarmos com as pessoas mais velhas".

d) "Não existe nos outros países, só na nossa ilha".

e) "Para diferenciarmos dos outros países africanos". 
f) "Para mostrar nossa cultura no exterior".

g) "Quando viajamos logo as pessoas vão saber que você não é de lá e vão te perguntar de onde vens. 'Da Ilha do Príncipe'. Eles te dizem ‘fala um pouco de lung'le' e [se] você não sabe falar, é vergonha."

h) "Se outros países ensinam a língua materna deles, nós devemos também saber a nossa".

\subsection{SIINTESE}

Nessa seção, buscamos apresentar um rol de atitudes em relação ao lung'le à partir de comentários sobre questões referentes ao ensino e à identidade, recolhidos nos questionários e nas entrevistas realizadas com os professores e alunos. Desse modo, na subseção 5.1 (subseções 5.1.1 a 5.1.3), foram apresentados comentários e reflexões dos professores com relação às dificuldades encontradas para o desenvolvimento de seu trabalho (5.1.1); ao planejamento das aulas e à ortografia (5.1.2) ; e, por fim, à identidade étnica e linguística com o lung’le (5.1.3). Na subseção 5.2, observamos os comentários feitos pelos alunos no que diz respeito à sala de aula (5.2.1); às suas preferências e o que poderia melhorar no ensino (5.2.2); e, por fim, discutimos a relação identitária que o aluno demonstra ter com a língua em 5.2.3. Diante disso, na seção 6, discutiremos propostas de intervenção para o ensino e a aprendizagem do lung'le.

\section{PROPOSTAS DE INTERVENÇÃO}

Nesta seção, serão apresentadas algumas propostas para a melhoria do ensino do lung'le no sistema escolar de São Tomé e Príncipe, tendo como base as respostas aos questionários e entrevistas feitos com os professores e alunos do Príncipe.

Acreditamos que as seguintes medidas básicas sejam necessárias para melhorias no ensino do lung'le:

Oferecimento de cursos sobre o ALUSTP para professores e outros interessados e implementação do ALUSTP pelos professores na sala de aula;

$\square$ Publicação e distribuição de métodos pedagógicos, dicionários e difusão de estudos sobre o lung'le, e distribuição de materiais didáticos e paradidáticos online e impressos para professores e alunos do Príncipe; 
Cursos de formação para os professores, utilizando, por exemplo, o método pedagógico de Agostinho (2014);

Melhoria da condição salarial e laborativa dos professores de lung'le (transporte, alimentação, infraestrutura de sala de aula, acesso a materiais didáticos e escolares, etc.);

Proposição de métodos didáticos que também privilegiam a interação professor-aluno;

Promover o engajamento em atividades de difusão do lung'le na comunidade, como o Palixa na lung'le, concursos culturais, programas radiofônicos e televisivos, criação de zines, eventos de culinária e medicina tradicional, etc;

Ministrar cursos e palestras sobre preconceito linguístico e línguas nacionais, focando em sua importância para a identidade principense.

Os instrumentos linguísticos permitirão uma maior estabilidade na metodologia de ensino (Auroux 1998), auxiliando professores e alunos, já que sua inexistência gera uma dificuldade para o ensino da língua nas escolas, uma vez que a escola e o sistema de ensino são os canais mais eficientes no planejamento linguístico (WEIJER 2008). Junto a isso, a difusão do ALUSTP entre os professores ampliaria o alcance dos instrumentos linguísticos como um todo. Ao mesmo tempo, cursos de formação de professores direcionados à aplicabilidade do método de Agostinho(2014), bem como cursos de aperfeiçoamento didático em geral poderiam auxiliar na melhoria da qualidade das aulas. Ademais, ensinar os professores a utilizarem os recursos do método (AGOSTINHO 2014) poderia fazer com que a padronização das aulas aumentasse. Quanto ao papel do Governo Regional e dos responsáveis pela educação, seria interessante discutir e promover políticas públicas de melhoria da infraestrutura, como por exemplo, melhorar as condições de transporte e alimentação para os professores e incentivar os alunos a participarem das atividades promovidas pela escola e pelo Centro Cultural do Príncipe. Além disso, os professores deveriam ter acesso a materiais didáticos e escolares diversos para utilização na preparação de aulas e na sala de aula e instrumentos linguísticos, além dos cursos de formação para o adequado uso desses materiais. Ao mesmo tempo, poderiam ser promovidas atividades para incentivar os estudantes a participar mais das aulas, como a utilização de música, teatro, etc. A falta de material didático é um dos problemas comumente mencionados pelos alunos, sendo assim, acreditamos que a implementação desses instrumentos linguísticos despertaria maior interesse nos alunos em relação ao lung'le. 
Por fim, atividades de difusão do lung'le e sobre a cultura do Príncipe na comunidade ajudariam a manter a língua em uso pelos mais velhos e a incentivar seu aprendizado pelos mais novos. É essencial que o falante possa ter um motivo para aprender uma língua minoritária, seja ele participar de forma mais ativa na comunidade, se comunicar com os mais velhos, preservar sua identidade, poder participar de certas atividades, entre outros.

\section{CONSIDERAÇÕES FINAIS}

Makoni \& Meinhof (2006) defendem uma política linguística escolar que incorpore a consciência sociolinguística como parte do currículo nas regiões africanas. Na mesma linha, Fishman (2006) defende que as línguas minoritárias deveriam ser consideradas como recursos naturais de uma nação, imprescindíveis para seu enriquecimento linguístico e cultural e que funcionam como um diferencial diante da globalização. $\mathrm{O}$ autor também sugere que as políticas linguísticas devem ser centradas na democracia cultural. Orlandi (2009) salienta que o objetivo de uma política linguística deve ser preservar e maximizar o desenvolvimento etnolinguístico e promover o uso da língua em questão na vida social, econômica e política da nação. Sendo assim, advogamos aqui por uma política linguística, nos termos de Webb (2009), que inclua os falantes e os mais velhos como parte essencial de sua execução e não que haja imposição, como foi feito com o português em STP no início do século XIX (cf. AGOSTINHO 2014). Nesse sentido, a reivindicação de representantes do Príncipe nas próximas decisões relacionadas à política linguística é legítima. No que diz respeito à criação de materiais linguísticos, é importante que os autores enfatizem a contribuição dos falantes em sua elaboração. No caso das aulas e dos encontros, é interessante ter os mais velhos como centro da discussão e como professores, mas há a necessidade de acompanhamento de especialistas junto a eles. Dessa forma, acreditamos que a aceitação da população em geral será mais ampla em relação aos instrumentos linguísticos e às aulas na escola.

O lung’le está em perigo de extinção, mas as atitudes em relação à língua têm se tornado positivas nos últimos anos, sugerindo um possível quadro de reversão do risco. Além disso, o fato de falantes de línguas minoritárias terem atitudes linguísticas negativas em relação à sua língua não significa que não dão valor social e afetivo a ela (RODRIGUES 2012), o que pode ser observado nas respostas dos alunos, uma vez que muitos não têm interesse em participar das aulas e atividades, mas demonstram relacionar a língua à sua identidade cultural. Sendo assim, cursos 
e palestras sobre preconceito linguístico e línguas nacionais poderiam auxiliar nessa transição do simbólico, a identidade, para o concreto, as aulas de lung’le. Esses cursos e palestras também auxiliariam a disseminar a ideia que línguas crioulas não são versões erradas das línguas dos colonizadores, mas línguas novas com regras próprias (HOLM 1988, p. 1).

\section{AGRADECIMENTOS}

Agradecemos à Professora Ester Espírito Santo pelo auxílio na ocasião da distribuição dos questionários e a todos os professores, alunos e pais de alunos envolvidos nesta pesquisa.

\section{REFERÊNCIAS BIBLIOGRÁFICAS}

AGOSTINHO, A. L. S. Faa Ningê Bê: Aspectos de uma Gramática Pedagógica para a Língua Crioula Principense. In: XII e XIII Encontros dos Alunos de Pós-Graduação em Linguística da USP, São Paulo, 2012. Anais... São Paulo: Universidade de São Paulo, 2012. pp. 53-67.

AGOSTINHO, A. L. S. Fonologia e método pedagógico do lung'Ie. 2014. Tese (Doutorado em Letras) - Faculdade de Filosofia, Letras e Ciências Humanas, Universidade de São Paulo, São Paulo.

APPEL, R.; VERHOEVEN, L. Decolonization, Language Planning and Education. In: ARENDS, J; MUYSKEN, P.; SMITH, N. Pidgins and Creoles: An Introduction. Amsterdam / Philadelphia: John Benjamins, 1995.

ARAÚJO, G. A. Três textos em papiamentu clássico. 2011. Tese (Livre-Docência em Letras) Faculdade de Filosofia, Letras e Ciências Humanas, Universidade de São Paulo, São Paulo.

ARAÚJO, G. A.; AGOSTINHO, A. L. S. Padronização das línguas nacionais de São Tomé e Príncipe. Lingua e Instrumentos Linguísticos 26, pp. 49-81, 2010.

ARAÚJO, G. A.; AGOSTINHO, A. L. S.; BANDEIRA, M. Dicionário lung'le-português. Em preparação.

ARENDS, J. The Socio-historical Background of Creoles. In: ARENDS, Jacques; Pieter Muysken; SMITH, Norval. Pidgins and Creoles: An Introduction, John Benjamins, 1994.

AUROUX, S. A revolução tecnológica da gramatização. Campinas: Editora da Unicamp, 1992.

AUROUX, S. Língua e hiperlíngua. In: ORLANDI, E. P.; GUIMARÃES, E. Língua e instrumentos linguísticos. Campinas: Pontes Editores, 1998. 
CAGLIARI, Luiz Carlos. Prosódia: algumas funções dos supra-segmentos. In: ABAURRE, Maria B. M.; WETZELS, W. Leo. Cadernos de Estudos Lingüísticos: Fonologia do Português. Campinas: UNICAMP, IEL, DL, pp. 137-151, 1994.

CHRISTOFOLETTI, Alfredo. Ditongos do português de São Tomé e Príncipe. 2013 Dissertação (Mestrado em Letras), - Faculdade de Filosofia, Letras e Ciências Humanas, Universidade de São Paulo, São Paulo.

DEVONISH, Hubert. Language Planning in Pidgins and Creoles. In: KOUWENBERG, Silvia; SINGLER, John Victor. The Handbook of Pidgin and Creole Studies. Oxford: Blackwell, pp. 615-636, 2008.

ESPÍRITO SANTO, Ester. O lung'Ie na Ilha do Príncipe. Em preparação. Monografia (Trabalho de Conclusão de Curso) - Universidade de São Tomé e Príncipe, São Tomé.

FERRAZ, L. A origem e desenvolvimento dos quatro crioulos portugueses do Golfo da Guiné. Revista brasileira de linguística vol.3, n.2, 1976.

FIORIN, José Luiz. Linguagem e ideologia. São Paulo: Ática, 1993.

FISHMAN, Joshua A. Language Maintenance, Language Shift, and Reversing Language Shift. In: BHATIA, Tej K.; WILLIAM, C. Ritchie (eds.). The Handbook of Bilingualism. Oxford: Blackwell, pp. 406-436, 2006.

GUISAN, Pierre. Língua: a ambiguidade do conceito. São Paulo: Contexto, 2009.

GÜNTHER, Wilfried. Das portugiesische Kreolisch der Ilba do Príncipe. Marburg an der Lahn: Im Selbstverlag, 1973.

FREITAS, Shirley. O ensino do papiamentu em Curaçao e do kabuverdianu de Santiago. Projeto de pós-doutorado. Em preparação.

HOLM, John. Pidgins and Creoles vol.1. Cambridge: CUP, 1988.

INSTITUTO NACIONAL DE ESTATÍSTICA. INE: São Tomé e Príncipe em números. 2001 Disponível em: <http://www.ine.st/files \_pdf/STP \numeros \2006.pdf>. Acesso em: 21 junho 2011.

INSTITUTO NACIONAL DE ESTATÍSTICA. INE: São Tomé e Príncipe em números. 2012. Disponível em: <http://www.ine.st/docs/2012/Censos/2012/index.html>. Acesso em: 07 agosto 2013.

MAKONI, S.; MEINHOF, U. Linguística aplicada na África: desconstruindo a noção de língua. In: LOPES, L. P. de M. (Org.). Por uma linguística aplicada indisciplinar. São Paulo: Parábola, pp. 191-213, 2006.

MAURER, P. Principense. Londres: Battlebridge Publications, 2009.

ORLANDI, Eni P. Processos de descolonização linguística: as representações da língua nacional. In: GALVES, Charlotte, HELDER, Garmes; RIBEIRO, Fernando Rosa (org.). África-Brasil: caminhos da língua portuguesa. Campinas: Editora UNICAMP, pp. 211-223, 2009.

PINHO, Isis da Costa. Diversidade lingüística e Identidade: as micro-decisões na manutenção/perda de uma língua materna minoritária. Contingentia 3, n.1: pp. 78-94, 2008. 
PONTÍFICE, João; CAUSTRINO Alcântara; AFONSO, Beatriz de Castro; HAGEMEIJER, Tjerk; MAURER, Pbilippe. Alfabeto Unificado para a Escrita das Línguas Nativas de S. Tomé e Príncipe (ALUSTP). 2010.

RODRIGUES, Luiz Carlos Balga. Atitude, imaginário, representação e identidade linguística: aspectos conceituais. In: XVI CNLF. Anais... Cadernos do CNLF, Vol. XVI, No 04, 2012. pp. 362-373.

SEVERING, Ronald; WEIJER, Christa. The Fundashon pa Planifikashon di Idioma: Language Planning and Language Policy in Curaçao. In: FARACLAS, Nicholas, SEVERING, Ronald Esperano; WEIJER, Christa M. Roose. Linguistic Studies on Papiamentu. Curaçao: Fundashon pa Planifikashon di Idioma, pp. 247-260, 2010.

STP. Direcção de Estatística. 1o. Recenseamento geral da população e da babitação. [Sao Tome?]: República Democrática de S. Tomé e Principe, Ministério do Plano, Direcção de Estatística, 1987.

VAUX, Bert; COOPER, Justin; TUCKER, Emily. Linguistic Field Methods. Oregon: Wipf \& Stock, 2007.

WEBB, V. Multilingualism in South Africa: The Challenge to Below. Language Matters: Studies in the Languages of Africa 40, n.2, pp. 190-204, 2009. 


\section{ANEXO}

A seguir reproduziremos as perguntas referentes aos questionários dos professores e alunos.

\section{Questionário - Professores}

Nome:

Idade:

Série(s) em que leciona:

Escola(s) onde leciona:

Por que o lung'le deveria ser ensinado na escola?

2. Você gosta de dar aulas de lung'le? Por quê?

3. Você acha que o lung'le deveria ser matéria obrigatória? Por quê?

4. Você acha importante os jovens aprenderem lung'le? Por quê?

5. O que você mais gosta nas aulas de lung'le?

6. O que você menos gosta nas aulas de lung'le?

7. O que você acha que poderia melhorar nas aulas de lung'le?

8. Qual sua maior dificuldade para ensinar lung'le?

9. Como é o planejamento das aulas de lung’le?

10. Como é sua relação com outros professores de lung'le?

11. Como você decide como escrever em lung'le?

12. Você acha que deveria haver um modo de escrever unificado? 
13. O Governo ofereceu alguma formação de professor para você?

14. Você tem alguma formação? Gostaria de ter?

\section{Questionário - Alunos}

Nome:

Idade:

Série:

Escola onde estuda:

Professor de lung'le:

1. Você vai às aulas de lung'le?
( ) sempre
( ) quase sempre
( ) às vezes
( ) quase nunca
( ) nunca

2. Você vai ao Palixa na lung'le?
( ) sempre
( ) quase sempre
( ) às vezes
( ) quase nunca
( ) nunca

3. Você ouve o programa de rádio em lung'le?
( ) sempre
( ) quase sempre
( ) às vezes
( ) quase nunca
( ) nunca

4. Você acha que o lung'le deveria ser ensinado na escola? Por quê?

5. Você gosta das aulas de lung'le? Por quê?

6. Você aprende com as aulas de lung'le? O que você já aprendeu?

7. Você participa nas aulas de lung'le? Como?

8. Você acha que o lung’le deveria ser matéria obrigatória? Por quê?

9. Você acha importante aprender lung'le? Por quê? 
10. Você quer aprender lung'le? Por quê?

11. O que você mais gosta nas aulas de lung'le?

12. O que você menos gosta nas aulas de lung'le?

13. O que você acha que poderia melhorar nas aulas de lung'le?

14. O que você gostaria de aprender nas aulas de lung'le?

Recebido: 24/07/2016

Aceito: 06/10/2016 


\section{ERRATA}

Artigo: O LUNG'IE NA EDUCAÇÃO ESCOLAR DE SÃO TOMÉ E PRÍNCIPE

Publicação: Trab. linguist. apl. v55n3a3, 591-618, Campinas set./dez. 2016

DOI: bttp://dx.doi.org/10.1590/010318135164183401

Pág 591 - Nome do Estado repetido no título do artigo

Onde se lia:

O LUNG'IE NA EDUCAÇÃO ESCOLAR DE SÃO TOMÉ SÃO TOMÉ E PRÍNCIPE

Leia-se:

O LUNG'IE NA EDUCAÇÃO ESCOLAR DE SÃO TOMÉ E PRÍNCIPE

Pág 613 - Modificar o nome de autora nas Referências. O nome completo é Manuele Bandeira de Andrade Lima, ficou LIMA, e ela usa BANDEIRA...

Onde se lia:

AraúuO, G. A.; AGOSTinhO, A. L. S.; LiMA, M. B. A. Dicionário lung’leportuguês. Em preparação.

Leia-se:

ARAújO, G. A.; AGOSTiNHO, A. L. S.; BANDEIRA, M. Dicionário lung’leportuguês. Em preparação. 